\title{
Lessons learned about appendiceal neuroendocrine neoplasms from data analysis of the Belgian Cancer Registry 2010-2015
}

S. Ribeiro ${ }^{1}$, F. De Maeyer², M. De Man', S. Carton 3 , P.J. Cuyle ${ }^{3}$, C. Verslype ${ }^{4}$, I. Borbath ${ }^{5}$, P. Demetter ${ }^{6}$, N. Van Damme', L. Van Eycken ${ }^{7}$, T. Vandamme ${ }^{8}$, A. Hoorens ${ }^{9}$, K. Geboes ${ }^{1}$

(1) Gastroenterology Department, UZ Gent, Gent, Belgium ; (2) Gastroenterology Department, Sint-Elisabeth Ziekenhuis, Zottegem, Belgium ; (3) Gastroenterology and Digestive Oncology Department, Imelda General Hospital, Bonheiden, Belgium ; (4) Gastroenterology Department, UZ Leuven, Leuven, Belgium ; (5) Gastroenterology Department, UCLouvain, Louvain, Belgium; (6) Department of Pathology, Institut Jules Bordet, ULB, Brussels, Belgium ; (7) Belgian Cancer Registry, Brussels, Belgium ; (8) NETwerk and Department of Oncology, Antwerp University Hospital and University of Antwerp, Antwerpen, Belgium ; (9) Department of Pathology, Ghent University Hospital, Ghent, Belgium.

\begin{abstract}
Background and study aims: Appendiceal neuroendocrine neoplasms (aNENs) are a diverse group of malignant neoplasms of varying biological behavior for which information about management and outcome is sparse, with the majority of available studies being retrospective, including only a limited number of patients, and therefore not necessarily reflecting the reality in the community. In the present study clinical, epidemiological and pathological data of appendiceal neuroendocrine neoplasms in Belgium is provided and compared with current literature.

Methods: A population-based study was conducted by linking data of the Belgian Cancer Registry with medical procedures in the Belgian Health Insurance database for patients diagnosed with aNEN between 2010 and 2015.

Results: We found an aNEN incidence of $0.97 / 100.000$ person years in Belgium. Neuroendocrine carcinoma of the appendix are rare. Most appendiceal neuroendocrine tumors (aNETs) are small G1 tumors. Positive lymph nodes are often found in tumors larger than $2 \mathrm{~cm}$, especially aNET G2.

Conclusion: A rapid uptake of changing classifications was seen in the community. However, systematic reporting of risk factors for small aNEN can still be improved and should be stimulated. In $9 \%$ of cases, reclassifications had to be made, pointing out that in a retrospective analysis, original pathological reports should be checked for specific parameters, before reliable conclusions can be drawn. (Acta gastroenterol. belg., 2021, 84, 458-466).
\end{abstract}

Keywords: tumor, population-based study, appendix, quality, report, management.

\section{Introduction}

Appendiceal neuroendocrine neoplasms (aNENs) often present with acute appendicitis or can be found incidentally during abdominal surgeries. aNEN is found in one in 300 patients undergoing appendectomy (1). The reported incidence is 0.1 to $0.6 / 100,000$ inhabitants/year in population based studies, with the highest incidence in women below 40 years of age (2-5).

Before 2010, neuroendocrine neoplasms were classified into well- and poorly differentiated endocrine neoplasms based on morphology. In 2007, ENETS (the European Neuroendocrine Tumor Society) proposed a grading system comprising mitotic count (per 10 high power fields, HPF) and Ki-67 index that was subsequently incorporated in the World Health Organization (WHO) classification $(6,7)$. Final grade is based on whichever index (mitotic rate/Ki-67 index) places the tumor in the highest category and if discordance, the Ki-67 index will generally indicate the higher grade (8).

New evidence has shown that neuroendocrine tumors (NETs) are genetically distinct from poorly differentiated neuroendocrine carcinoma's (NECs) and this has been taken into account in the WHO classification of 2019 (9). The WHO Classification of Tumors (Blue Books) project was initiated by WHO through a resolution of the WHO Executive Board in 1956 (9). The objective of the WHO Classification of Tumors is to provide a uniform nomenclature of human cancers that is accepted and used worldwide. At the level of genetic alterations, NEC show mutations in TP53, KRAS, and BRAF, while NET present mutations in MEN1, ATRX-DAXX, PI3k/AKT/ mTOR, and TGF- $\beta$ pathways (10).

NECs are separated into small- and large-cell types (large cell NEC-LCNEC and small cell NEC-SCNEC) with mitotic count $>20 / 10 \mathrm{HPF} / \mathrm{Ki}-67$ index above $20 \%$ (11). Well-differentiated NETs are divided in 3 groups : well differentiated NET G1 (low grade) with mitotic count $<2 / 10 \mathrm{HPF} / \mathrm{Ki}-67$ below 3\%; well-differentiated NET G2 (intermediate grade) with mitotic count 2-20/10 HPF/Ki-67 index between 3-20\%; well differentiated NET G3 (high grade) with mitotic count $>20 / 10 \mathrm{HPF} /$ Ki-67 index $>20 \%$ (9).

The prognostic role of Ki-67 labeling index has already been validated in several studies and is recognized as a highly reproducible and powerful tool in NENs. Although NET G3 appear to have a worse prognosis than NET G2, their behavior is still less aggressive than that of NEC.

For instance, in one study NETs G3 were associated with a median overall survival (mOS) of 24.5 months, whereas NECs had a mOS of 12.9 months or 5.3 months, depending on a Ki-67 labeling $>$ or $\leq 55 \%$ (12).

Specifically for appendiceal NENs, size has been defined as the most reliable indicator for metastatic potential $(4,13,14,15,16)$. Other factors that should also be considered are mesoappendix invasion (MAI), pre-

Correspondence to : Suzane Ribeiro, Gastroenterology, UZ Gent, Corneel Heymanslaan 10, Gent, 9000, Belgium. Fax: 093324984.

E-mail: suzane.ribeiromoura@uzgent.be

Submission date : 29/11/2020

Acceptance date : 08/03/2021 


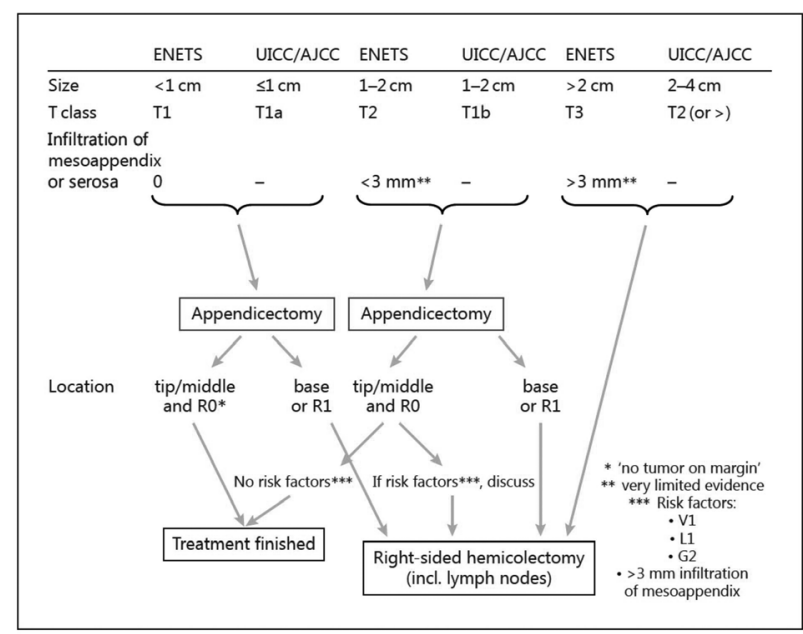

Figure 1. - Management strategies for appendiceal neuroendocrine neoplasms suggested by the European Neuroendocrine Tumor Society. V1=vascular invasion; L1=lymphatic invasion; G2=grade 2 tumor (Ki-67 :3-20\%) (17).

sence of lymphovascular invasion, location at the base of the appendix, positive resection margins or high proliferative index (Figure 1) (17). These criteria are used to decide upon additional right hemicolectomy (RHC) (17).

Unfortunately, guidelines about the appropriate management of these tumors lack strong evidence firstly because of their relatively low incidence and their heterogeneity, secondly because of the recurrent changes in the classification systems in the past 15 years and finally because of insufficient established criteria for quality control of pathology reporting, which can lead to misclassification and consequently impaired interpretation of outcomes (18). In literature, most data on management of aNENs are collected from institutional series suffering from referral bias.

Data on epidemiology of aNENs are retrieved from national databases with different systems of input that can influence numbers. The mandatory registration in a tax-based health system in Belgium allows for complete numbers. Moreover, data from the Belgian Cancer Registry (BCR) can be compared with the anonymized full pathological reports, allowing adaptation of staging and grading towards the latest classification.

The BCR uses the ICD-O classification (International Classification of Diseases - Oncology) $(7,17,19,20)$. The International Classification of Diseases for Oncology has been introduced in 1976, principally in tumor or cancer registries, for coding the site (topography) and the histology (morphology) of the neoplasm, usually obtained from a pathology report (19). Since the publication of the third edition of ICD-O in 2000, updates to the WHO Blue Book series have continued. Chapter authors for the WHO Blue Book series worked with the International Classification of Diseases for Oncology Committee to review recently identified neoplasm entities and assign morphology codes. The updated version of ICD-O-3 includes the new terms, codes, synonyms, related terms, morphology and behavior code changes from the WHO Blue Books published between 2007 and 2010 (19).

Later updates in the WHO classification have not been incorporated yet. Therefore, NET G3 has not yet been included in the ICD-O classification and goblet cell carcinoid (GCC), that is classified as goblet cell adenocarcinoma and no longer considered as NEN in WHO 2019, is still included.

The aim of the present study is to gather data on epidemiology and management according to risk factors for aNENs in Belgium, corrected for the latest WHO classification.

\section{Materials and methods}

The BCR is a population-based registry, considered to be complete for incidences from 2004 onwards, and relying on a firm legal basis (21). Based on notifications from the oncology care programs and pathology departments, a broad set of patient and tumor characteristics is registered, using the national social security number as a unique patient identifier. This identifier allows coupling with reimbursement data covering diagnostic and therapeutic acts, as recorded by the health insurance companies (HIC). Health insurance being obligatory in Belgium, the HIC data can also be considered quasi-complete (99\%) at the Belgian population level. In this way, information was obtained about whether and when an additional RHC was performed in aNENs.

All aNENs diagnosed between $1 / 1 / 2010$ and $31 / 12 / 2015$ were retrieved from the BCR database. Patients were selected on the basis of the International Classification of Diseases for Oncology (ICD-O3) topography code $\mathrm{C} 18.1$ and morphology codes 8013, 8041-8045, 8150-8156, 8240-8249. Standard patient (incidence date, age, sex) and tumor (histology, stage) characteristics were available. More detailed tumor characteristics were derived from the pathology reports sent to the BCR as part of the pathology notification flow. The pathology reports (biopsies and surgeries) were reviewed case-by-case to extract information on Ki-67, number of mitosis, differentiation grade, tumor size, location, MAI, LN and lymphovascular involvement and margin status.

Reclassifications were made because of inconsistencies between the Ki-67 index mentioned in the pathological report and the final WHO grade but also because of inconsistencies in the grade of differentiation. On a second level, reclassifications were made towards the latest WHO classification.

All cases were checked for doubles, inconsistencies and misclassification. All questionable reports were discussed by at least 2 of the authors, after careful study of the full histological report.

As this study takes place within the legal framework of the BCR, no separate ethical approval is needed (13 december 2006 ; Kankerregister, B.S. 22 december 2006, p 73786 ; 8 december 1992 ; wet tot bescherming van de 
persoonlijke levenssfeer ten opzicht van de verwerking van persoonsgegevens, B.S. 18 maart 1993, p 5801).

The statistical analyses were performed using statistical software R (The R Project for Statistical Computing), version 4.0.0. Categorical variables were expressed as percentages, compared by the Fisher exact test when appropriate.

\section{Results}

\section{Pathology report}

$\underline{\text { Global analysis }}$

In total, 963 reports were gathered. Thirteen files were excluded because they were not neuroendocrine neoplasms $(n=6)$ or the origin of the tumor was not clear $(n=6)$ or the diagnosis was made based on a biopsy only $(\mathrm{n}=1)$. Two hundred fifty seven reports were doubles ( $\geq 2$ reports for the same patient).

Thus, during a 6-year period 693 patients were diagnosed with aNENs. The majority $(n=389 ; 56 \%)$ were women and the median age of diagnose was 38.5 (range 7-93) years.

Five hundred eighty four patients were diagnosed as NET grade 1 (NET G1), 16 as NET grade 2 (NET G2) and 6 as NEC on the basis of the original report. No NET grade 3 or small cell NEC were found. Forty goblet cell carcinoid (GCC), 24 adenocarcinoids and 23 mixed adenocarcinoma-neuroendocrine carcinoma's (MANECs), as defined by the ICD-O-3 classification were seen. The GCC, adenocarcinoids and MANECs were not withheld for further analysis. Indeed, these data will not be complete if we do not control for misclassified adenocarcinoma's.

All available pathology reports were reviewed and reclassifications were made as explained in the methods section.

Detailed analysis and reason of reclassification on the basis of original reports (Figure 2)

\section{NET grade 1}

In $13(2 \%)$ patients, the BCR did not have access to the complete report, $14(2,4 \%)$ patients had a Ki-67 of

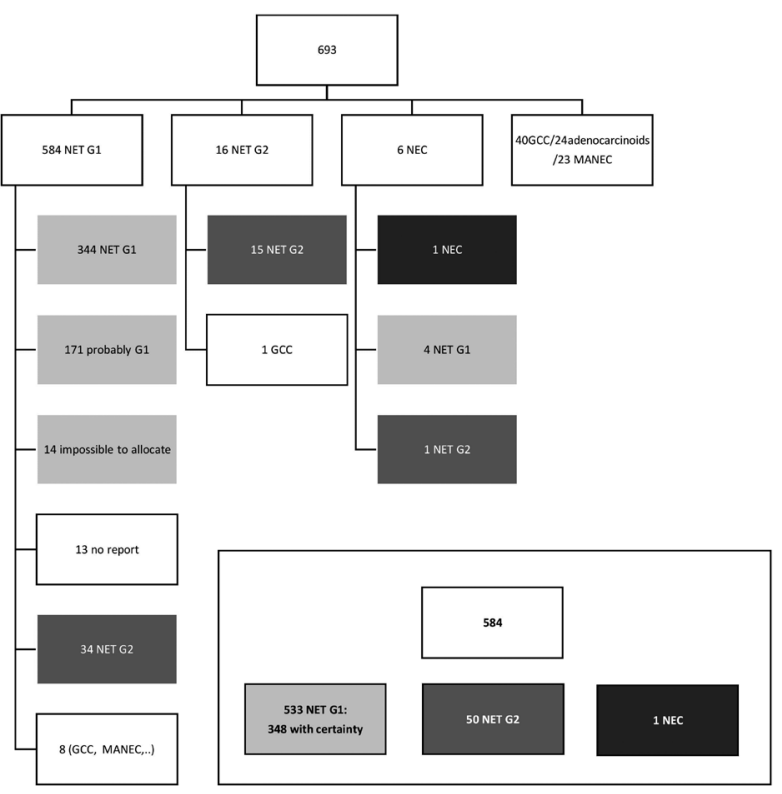

Figure 2. - Flowchart showing the original figures and the numbers after reclassification. G1=grade 1 tumor; G2=grade 2 tumor ; NET : neuroendocrine tumor ; NEC : neuroendocrine carcinoma; GCC : goblet cell carcinoid; MANEC : mixed adenocarcinoma-neuroendocrine carcinoma.

less than 5\%, making it impossible to allocate them with certainty as NET G1 or G2. In 171 (29,3\%) files Ki-67 index was not mentioned or non-standard terms ("low", "high", "rare", "negative") were used, making classification impossible.

In 344/584 (59\%) of patients reported with NET G1, the classification was in concordance with the Ki-67 index mentioned in the full reports.

Forty two $(7,2 \%)$ tumors had been wrongfully classified as NET G1 : 34 were reclassified as NET G2 because of a Ki-67 index of more than $3 \% ; 1$ case had a $\mathrm{Ki}-67$ of $30 \%, 6$ had identification of goblet cells in the histology report ; 1 was described as MANEC with poor differentiation in the original report.

Four patients who had been originally recognized as NEC should have been included in the NET G1 group.

Therefore, we withhold 348 patients with "confirmed" NET G1, 171 possible NET G1 patients, and 14 patients considered impossible to allocate (Table 1).

Table 1. - Overview of the number and demographic characteristics of patients diagnosed with appendiceal neuroendocrine neoplasms in Belgium in the period 2010-2015 (after reclassification)

\begin{tabular}{|c|c|c|c|c|c|c|}
\hline & $\begin{array}{c}\text { Total } \\
(n=584)\end{array}$ & $\begin{array}{c}\text { NET grade } 1 \\
(n=348)\end{array}$ & $\begin{array}{c}\text { Probably NET grade } 1 \\
(n=171)\end{array}$ & $\begin{array}{l}\text { Impossible to allocate } \\
(\mathrm{n}=14)\end{array}$ & $\begin{array}{c}\text { NET grade } 2 \\
(n=50)\end{array}$ & $\begin{array}{c}\text { Large cell NEC } \\
(n=1)\end{array}$ \\
\hline \multicolumn{7}{|c|}{ Age at diagnosis (years) } \\
\hline Median & 36 & 36 & 37 & 32,5 & 26 & 58 \\
\hline Range & $7-91$ & $7-91$ & $8-90$ & $11-56$ & $7-69$ & 58 \\
\hline \multicolumn{7}{|c|}{ Gender $(\%)$} \\
\hline Male & $251(43)$ & $147(42,2)$ & $79(46,2)$ & $5(35,7)$ & $20(40)$ & $0(0)$ \\
\hline Female & $333(57)$ & $201(57,8)$ & $92(53,8)$ & $9(64,2)$ & $30(60)$ & $1(100)$ \\
\hline
\end{tabular}

NEC: neuroendocrine carcinoma ; NET: neuroendocrine tumor. 


\section{NET grade 2}

We originally found 16 patients classified as NET G2, 1 of whom had in fact a GCC.

Thirty-four patients with a Ki-67 index between 3\% and $20 \%$ were incorrectly stratified as NET G1 and another one was initially classified as NEC. So after reclassification, there were 50 patients with NET G2.

This may be an underestimation, because we lack exact information on Ki-67 index in 171 patients coded as G1 tumors, and 14 patients with a Ki-67 index valued below $5 \%$.

\section{NEC}

6 patients were described as having NECs, but in fact only one of them had a tumor with poor histological differentiation. Among the other 5 patients, 4 were NET G1 and 1 NET G2 on the basis of the Ki-67 indices.

In conclusion, 583 patients with aNET and 1 patient with aNEC were withheld, after thorough review and reclassification, with median age of 36 years and a female predominance $(\mathrm{n}=333 ; 57 \%)$. This allows for an incidence of $0.97 / 100.000 / y$.

\section{Management after reclassification}

In this section we focus on the 584 patients with aNENs after review of the original reports and reclassification.

\section{Context of first surgery}

Most aNENs were detected incidentally, either in the context of acute appendicitis (44\%) or surgery for colonic neoplasm (6,7\%) (Figure 3).

In the vast majority of cases, primary surgery comprised a simple appendectomy $(78,7 \%)$ or a right hemicolectomy (RHC) with lymph node (LN) resection $(9,6 \%)$. In 24 cases the appendix was removed in the context of urogynecological procedures (Figure 4).

\section{Overall quality of the reporting of aNET and its risk factors}

Fluctuations in reporting through the years were summarized in Table 2. This is partly explained by changes in the classification system.

Risk factors that need to be discussed in order to make a sound decision on the need for additional surgery comprise size/stage, location, Ki index, MAI, lymphovascular involvement and margin status.

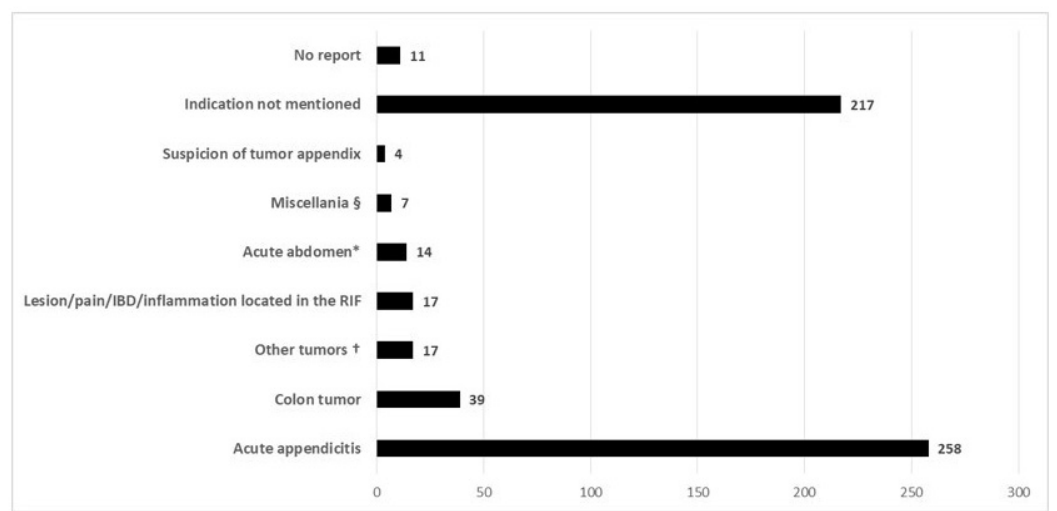

Figure 3. - Indication of first surgery for the 584 patients with appendiceal neuroendocrine neoplasms. $\uparrow$ urothelium, leiomyosarcoma, ovarium, cervix, bladder, teratoma, pseudo-myxoma, prostate. * perforation, volvulus, ischemia, diverti-culitis, obstruction. $\S$ debulking, hysterectomy, stoma reversal surgery, cyst ovarium, dolichocolon, hernioplastia. IBD : in-flammatory bowel disease ; RIF : right iliac fossa.



Figure 4. - Type of first surgery for the 584 patients with appendiceal neuroendocrine neoplasms. * debulking, stoma reversal surgery, rectum resection, left hemicolectomy, chole-cystectomy, resection segment small bowel. 
Table 2. - Overview and evolution of pathology reports for the appendiceal neuroendocrine neoplasms (after reclassification)

\begin{tabular}{|l|c|c|c|c|c|c|c|}
\hline & Total & $\mathbf{2 0 1 0}$ & $\mathbf{2 0 1 1}$ & $\mathbf{2 0 1 2}$ & $\mathbf{2 0 1 3}$ & $\mathbf{2 0 1 4}$ & $\mathbf{2 0 1 5}$ \\
\hline Total (n) & $\mathbf{5 8 4}$ & $\mathbf{8 0}$ & $\mathbf{9 1}$ & $\mathbf{1 0 5}$ & $\mathbf{1 1 2}$ & $\mathbf{8 9}$ & $\mathbf{1 0 7}$ \\
\hline Ki-67 & $408(70 \%)$ & $35(43,8 \%)$ & $60(66 \%)$ & $71(67,6 \%)$ & $86(76,8 \%)$ & $70(78,6 \%)$ & $86(80,4 \%)$ \\
\hline Mitotic index & $217(37,2 \%)$ & $31(38,8 \%)$ & $31(34 \%)$ & $40(38 \%)$ & $41(36,6 \%)$ & $36(40,4 \%)$ & $38(35,5 \%)$ \\
\hline Grade of differentiation & $344(59 \%)$ & $35(43,8 \%)$ & $38(41,8 \%)$ & $55(52,4 \%)$ & $71(63,4 \%)$ & $68(76,4 \%)$ & $77(72 \%)$ \\
\hline Size of tumor & $546(93,5 \%)$ & $70(87,5 \%)$ & $84(92,3 \%)$ & $102(97 \%)$ & $109(97,3 \%)$ & $85(95,5 \%)$ & $96(89,7 \%)$ \\
\hline Location at the appendix & $458(78,4 \%)$ & $56(70 \%)$ & $71(78 \%)$ & $86(82 \%)$ & $87(77,7 \%)$ & $79(88,7 \%)$ & $79(73,8 \%)$ \\
\hline Mesoappendix infiltration & $100(17,1 \%)$ & $16(20 \%)$ & $19(21 \%)$ & $20(19 \%)$ & $20(17,9 \%)$ & $11(12,4 \%)$ & $14(13 \%)$ \\
\hline Lymphovascular involvement & $215(36,8 \%)$ & $21(26,2 \%)$ & $32(35 \%)$ & $31(29,5 \%)$ & $40(35,7 \%)$ & $40(45 \%)$ & $51(47,7 \%)$ \\
\hline Margin status & $321(55 \%)$ & $38(47,5 \%)$ & $49(54 \%)$ & $61(58 \%)$ & $59(52,7 \%)$ & $46(51,7 \%)$ & $68(63,5 \%)$ \\
\hline Staging (T) mentioned & $371(63,5 \%)$ & $36(45 \%)$ & $47(51,6 \%)$ & $70(66,7 \%)$ & $81(72,3 \%)$ & $63(71 \%)$ & $74(69,2 \%)$ \\
\hline $\begin{array}{l}\text { Staging (T) mentioned with exact information } \\
\text { on classification }\end{array}$ & $147(25 \%)$ & $15(18,7 \%)$ & $16(17,6 \%)$ & $25(23,8 \%)$ & $30(26,8 \%)$ & $31(35 \%)$ & $30(28 \%)$ \\
\hline
\end{tabular}

Table 3. - Prevalence of reporting risk factors according to size

\begin{tabular}{|l|c|c|c|c|c|}
\hline Report of prognostic factor & Total (584) & $\mathbf{1} \mathbf{c m}(\mathbf{3 8 2})$ & $\mathbf{1 - 2 c m}(\mathbf{1 1 2})$ & $\mathbf{>} \mathbf{2 c m} \mathbf{( 3 5 )}$ & Fisher's exact test (p-value) \\
\hline Location & $458(78,4 \%)$ & $313(82 \%)$ & $83(74 \%)$ & $27(77 \%)$ & $\mathrm{p}=0,1566$ \\
\hline Mesoappendix invasion status & $95(16 \%)$ & $52(13,6 \%)$ & $29(26 \%)$ & $10(28,5 \%)$ & $\mathrm{p}=0,001864$ \\
\hline LV involvement status & $209(35,8 \%)$ & $116(30 \%)$ & $64(57 \%)$ & $20(57 \%)$ & $\mathrm{p}<0,00001$ \\
\hline Resection margin status & $320(54,8 \%)$ & $202(52,9 \%)$ & $70(62,5 \%)$ & $19(54,3 \%)$ & $\mathrm{p}=0,1968$ \\
\hline
\end{tabular}

LV: lymphovascular.

Table 4. - Risk factors for lymph node positivity

\begin{tabular}{|c|c|c|c|}
\hline Number of RHC & LN - $(n=91)$ & $\mathbf{L N}+(\mathrm{n}=18)$ & Fisher's exact test (p-value) \\
\hline Tumor size & N (\%) & $\mathrm{N}(\%)$ & \\
\hline$\leq 1 \mathrm{~cm}$ & $33(36,2 \%)$ & $1(5,5 \%)$ & \multirow{3}{*}{$\mathrm{p}<0,0001$} \\
\hline $1-2 \mathrm{~cm}$ & $40(44 \%)$ & $2(11,1 \%)$ & \\
\hline$>2 \mathrm{~cm}$ & $15(16,5 \%)$ & $12(66,7 \%)$ & \\
\hline Not available & $3(3,3 \%)$ & $3(16,7 \%)$ & \\
\hline \multicolumn{4}{|l|}{ Tumor location } \\
\hline Base & $4(4,4 \%)$ & $7(38,9 \%)$ & \multirow{2}{*}{$\mathrm{p}=0,002$} \\
\hline Body/tip & $37(40,6 \%)$ & $6(33,3 \%)$ & \\
\hline Not available & $50(55 \%)$ & $5(27,7 \%)$ & \\
\hline \multicolumn{4}{|l|}{ Tumor grade } \\
\hline Grade 1 & $73(80,2 \%)$ & $10(55,6 \%)$ & \multirow{2}{*}{$\mathrm{p}=0,14$} \\
\hline Grade 2 & $13(14,3)$ & $5(27,8 \%)$ & \\
\hline Impossible to classify & $5(5,5 \%)$ & $3(16,7 \%)$ & \\
\hline \multicolumn{4}{|l|}{ Resection margins } \\
\hline R0 & $18(19,8 \%)$ & $5(27,7 \%)$ & \multirow{2}{*}{$\mathrm{p}=0,44$} \\
\hline R1 & $8(8,8 \%)$ & $5(27,7 \%)$ & \\
\hline Not available & $65(71,4 \%)$ & $8(44,4 \%)$ & \\
\hline \multicolumn{4}{|l|}{ Lymphovascular invasion } \\
\hline Yes & $19(20,8 \%)$ & $8(44,4 \%)$ & \multirow{2}{*}{$\mathrm{p}=1$} \\
\hline No & $7(7,7 \%)$ & $2(11,1 \%)$ & \\
\hline Not available & $65(71,4 \%)$ & $8(44,4 \%)$ & \\
\hline \multicolumn{4}{|l|}{ Mesoappendix involvement } \\
\hline Yes & $9(9,9 \%)$ & $3(16,7 \%)$ & \multirow{2}{*}{$\mathrm{p}=0,11$} \\
\hline No & $1(1 \%)$ & $3(16,7 \%)$ & \\
\hline Not available & $81(89 \%)$ & $12(66,7 \%)$ & \\
\hline
\end{tabular}

RHC: right hemicolectomy ; LN: lymph node.

Overall we observed a low rate of reporting risk factors other than size and WHO grade (Table 2). Size is almost always mentioned. We saw a steady rise in the reporting of the Ki-67 labelling, from $43,8 \%$ of cases in 2010 to $80,4 \%$ in 2015 . We also noticed a significant increase in the reporting of tumor differentiation grade to $>70 \%$ of reports after 2014 .
Because these parameters influence decisions more often in smaller tumors, we analyzed this subgroup specifically. Resection margin and lymphovascular invasion appear to be somewhat better reported in tumors with intermediate size (Table 3). 
Table 5. - Lymph nodes according to WHO grade and size

\begin{tabular}{|c|c|c|c|c|}
\hline & \multicolumn{2}{|c|}{ G1 } & \multicolumn{2}{|c|}{ G2 } \\
\hline \multirow[t]{2}{*}{$>2 \mathrm{~cm}$} & \multicolumn{2}{|c|}{21} & \multicolumn{2}{|c|}{6} \\
\hline & Immediate RHC & Additional RHC & Immediate RHC & Additional RHC \\
\hline \multirow[t]{2}{*}{ RHC } & \multicolumn{2}{|c|}{16} & \multicolumn{2}{|c|}{6} \\
\hline & 2 & 14 & 1 & 5 \\
\hline $\mathrm{LN}+$ & 1 & 5 & 1 & \\
\hline Residual disease and $\mathrm{LN}+$ & - & 2 & - & 3 \\
\hline Residual disease & - & 0 & - & 1 \\
\hline \multirow[t]{2}{*}{$1-2 \mathrm{~cm}$} & \multicolumn{2}{|c|}{71} & \multicolumn{2}{|c|}{15} \\
\hline & Immediate RHC & Additional RHC & Immediate RHC & Additional RHC \\
\hline \multirow[t]{2}{*}{ RHC } & \multicolumn{2}{|c|}{21} & \multicolumn{2}{|c|}{9} \\
\hline & 6 & 15 & 2 & 7 \\
\hline $\mathrm{LN}+$ & 1 & 0 & 0 & \\
\hline Residual disease and $\mathrm{LN}+$ & - & 0 & - & 0 \\
\hline Residual disease & - & 0 & - & 0 \\
\hline
\end{tabular}

RHC: right hemicolectomy; LN: lymph node.

\section{Outcome}

One hundred nine patients underwent RHC (with LN resection, either planned because of risk stratification or due to the fact that a right hemicolectomy had to be performed for other reasons) (Table 4). Eighteen patients had positive LN (16\%). A solid multivariate analysis on all risk factors for LN metastasis was not possible because of the amount of missing data. However, we did see that size and location at the base were significantly associated with LN metastasis.

Final analysis focuses on the 398 NET (348 G1 and $50 \mathrm{G} 2$ ) classified with certainty according to the WHO classification 2019 (Table 1).

\section{NET G1 according to WHO 2019 classification}

The size of the tumor and its location were reported in the majority of cases $(94,8 \%$ and $77,3 \%$, respectively). However, information concerning lymphovascular involvement, MAI and resection margin status was lacking in most files.

At least $51(14,6 \%)$ patients should have been discussed for RHC with LN dissection, because they had at least 1 indicative risk factor ( $\operatorname{size}>2 \mathrm{~cm}$, location at the base, microscopic margin involvement, lymphovascular invasion or MAI).

Of the 21 patients with NET G1 tumor $>2 \mathrm{~cm}$, only 16 had a RHC : six patients had positive LN (37,5\%), 2 also had residual disease (Table 5).

Seventy-one patients with NET G1 had a tumor with intermediate size. At least 1 of the 4 prognostic factors was missing for all patients ; 2 and 3 prognostic factors were missing for $28(39,4 \%)$ and $23(32,3 \%)$ patients respectively. On the basis of the ENETS guidelines, at least 30 patients should have been discussed for additional RHC. Of these patients, 21 received RHC. One patient had positive LN (4,8\%) (Table 5). Nine patients had RHC in absence of risk factors, 5 of them because of other tumors. None of them had residual disease or positive LN.

No information was found about the tumor location, the resection margin status and the mesoappendix in $46(19,3 \%), 113(47,5 \%)$ and $203(85,3 \%)$ of 238 patients, with tumor size $\leq 1 \mathrm{~cm}$. Thirty one patients had upfront RHC and only 1 of them had LN involvement, without a clear risk factor (location, LV involvement and mesoappendix status were not reported). 1 patient received additional $\mathrm{RHC}$ because of $\mathrm{R} 1$ resection but there was no residual tumor or LN involvement.

There was no size description in 18 tumors. One patient had additional RHC because of MAI. Two patients had additional RHC without known risk factor. None of them had residual disease or positive LN. Two patients that had upfront RHC had positive LN.

\section{NET G2 according to WHO 2019 classification}

Information about size and location of the tumor was available in $94 \%(n=47)$ and $84 \%(n=42)$ respectively. In $68 \%(n=34)$ of the reports, resection margins were mentioned.

Six patients with NET G2 had a tumor sized $>2 \mathrm{~cm}$ and all of them underwent RHC. Four had positive LN $(66,7 \%)$.

Fifteen patients had intermediate size NET G2 tumors. Only 1 patient had all risk factors reported while at least 1 prognostic factor was missing for the majority $(n=14$; $93,3 \%$ ) and 2 or more prognostic factors were missing for $7(46,7 \%)$ patients. No LN were found in any of the 9 patients who received RHC.

Twenty six patients had a tumor $\leq 1 \mathrm{~cm}$. Only 1 patient had all risk factors described and the majority $(n=25$; $96 \%$ ) had at least 1 missing prognostic factor. Apparently, 2 patients had a RHC (1 without clear risk factors) and no $\mathrm{LN}$ were found.

In 3 patients there was no information about the size of the tumor. Two of them had a R1 resection but only 1 
(that also had LV involvement) received additional RHC. This patient had positive LN.

\section{$\underline{\mathrm{NEC}}$}

The only patient with NEC had RHC with LN dissection as index surgery, showing involvement of $15 \mathrm{LN}$.

\section{Tumors impossible to be classified}

Among the 185 tumors that could not be classified with certainty because of missing data for grading, 8 had size $>2 \mathrm{~cm}$. Five of them had an additional RHC : 2 had positive $\mathrm{LN}, 1$ residual disease.

Of the 26 patients with tumors with intermediate size, 3 received additional RHC. Only 1 of them had a known risk factor ( $\mathrm{LV}$ involvement), but info on at least 1 risk factor was lacking in all files. One patient had residual disease and another had positive LN. The one with LV involvement had no positive LN or residual disease.

Thirty-four patients had no information on the size of their tumors.

\section{Discussion}

We identified 584 neuroendocrine neoplasms in Belgium over a period of 6 years : 583 neuroendocrine tumors (an incidence of $0.97 / 100.000 / y$ ) and 1 neuroendocrine carcinoma.

Our study confirmed that the majority of patients were female and diagnosis occurred often in the context of acute appendicitis $(5,17,22,23)$. The majority of patients had a NET grade 1 or 2 . The median age of patients in our series was 38.5 years.

We observed a stable annual incidence and we could see how reporting of risk factors evolved over the years. It is worthwhile comparing our data more specifically with those mentioned in a recent French series of 403 cases (4) : first because of the similar use of a modern classification system and secondly because the organization of care for NET patients in France is different from Belgium. In France, discussion in one of 12 referral centra for clinical (MDT RENATEN meeting) or pathological (TENpath) expert advice is strongly encouraged, but not mandatory. Our cohort comprises reports made by local pathologists, including experts, probably reflecting better the general knowledge the community. As the WHO classifications were updated, pathology records evolved with increasing description of Ki-67 index, and to a lesser degree differentiation grade and staging. Yet, we could still note a substantial underreporting of risk factors required to predict the need for additional intervention.

The percentage of missing data is substantially higher than in the French cohort, with missing data for size in $1,7 \%$ of cases, for localization in $24,3 \%$, for grading in $7,4 \%$, for mesoappendiceal invasion in $9,2 \%$, for lymphovascular invasion in $49,4 \%$ and for margin involvement in $6,4 \%$ of cases. We believe that this might be one of the reasons why in our study, only size and location at base were significantly associated with LN metastasis.
Size and grading are important to mention in all NETs. A reclassification was necessary due to discrepancies between the Ki-67 index mentioned in the report and the ICD-O coding used, showing the need to look into the original descriptions for scientific analysis. For consistency, reclassifications were made according to the WHO 2019 classification. In a considerable percentage $(31,7 \%, n=185)$ of cases the exact classification could not be completely verified due to missing data or use of nonstandardized terms.

We find 35 (21 G1, $6 \mathrm{G} 2$ and 8 patients that could not be classified) $/ 584(6 \%)$ tumors with a size $>2 \mathrm{~cm}$ and 112 (71 G1, $15 \mathrm{G} 2,26$ not possible to classify)/584 $(19,2 \%)$ tumors with intermediate size. In the French cohort, $8 \%$ of patients were $>2 \mathrm{~cm}$ and $30 \%$ of patients had a tumor size in between 1 and $2 \mathrm{~cm}$. The difference in prevalence is probably explained by referral patterns for discussion for the need of RHC. While we present a national analysis of all Belgian patients, the French cohort discusses 403 cases, so only referred cases. There might be an underrepresentation of small $(\leq 1 \mathrm{~cm})$ tumors.

Other risk factors, like location, resection margins, lymphovascular and MAI, are of course mostly important to consider in tumors with intermediate size. However, in our cohort, in all of those patients at least one risk factor necessary for management was missing. Nevertheless, missing information in prognostic factors was less frequent in these intermediate sized tumors when compared to the total. In Belgium, a significant part of pathologists use the College of American Pathologists (CAP) cancer reporting protocols, first introduced for NET in 2012. Of note, depth of MAI is not included in the CAP protocol template (24). Also, with the increasingly common laparoscopic approach for appendectomy, the mesoappendix is usually dissected (skeletonized) but left in situ, whereas open appendectomy involves en bloc mesoappendiceal resection (25).

Size is a consistent important factor in the management of aNENs. An analysis of a large series of aNETs demonstrated that a tumor size $>2 \mathrm{~cm}$ represents one of the most valuable predictive factors of LN metastasis (26), as confirmed in a systematic meta-analysis (27). Remarkably, not all reports contained information on size. Twenty-six out of 35 patients with a tumor $>2 \mathrm{~cm}$ in our cohort, had a RHC. Twelve patients had positive LN $(46,1 \%)$ and 7 (27\%) had residual (non-nodal) disease.

The management of the intermediate size aNETs is challenging. Up until recently, it was stated that RHC with LN dissection should be considered if there is involvement of the mesoappendix $>3 \mathrm{~mm}$, presence of angioinvasion or a high proliferative index (G2), location at the base of the appendix or positive margins (28). In our cohort, 42/112 patients with intermediate size had a RHC. Two had positive LN $(4,7 \%)$ and $1(2,4 \%)$ had residual disease. Some studies have shown that approximately half of the patients with aNETs of $1-2 \mathrm{~cm}$ that underwent RHC had lymph node metastases $(20,29,30,31)$. These retrospective studies don't show the overall risk in aNET 
with intermediate size, but suffer from a bias considering only intermediate size aNET that underwent RHC because of the presence of risk factors. In the French study (4), 38\% of patients with intermediate size aNET underwent a RHC. LN involvement was seen in $18 \%$ of patients who underwent surgery, and lymphovascular and perineural invasion were withheld as risk factors. In the Belgian community as well, $38 \%$ of patients with intermediate size aNET underwent a RHC. Only 2 patients $(5 \%)$ had positive LN. We may underestimate the risk on LN metastasis in this group because of the fact that not all patients with risk factors underwent surgery and because risk factors were underreported, meaning we may also underestimate the number of patients that should have been considered for surgery.

According to the ENETS guidelines, grading is important for the prediction of $\mathrm{LN}$ metastasis. Increased Ki-67 was associated with decreased survival in a retrospective study conducted in 2010 with a median follow-up of 40 months (10-183 months) (32). Small studies show a higher percentage of LN metastases in patients with high grade aNETS $(33,34)$. A recent publication on 72 patients referred to a tertiary center even suggested that tumor grade and lymphovascular invasion should be considered as the most important risk factors (35). On the other hand, a multicenter retrospective study did not find a correlation between grading and outcome in aNETS (36). NET grade 2 was found in $8,6 \%$ of our patients. Out of 100 patients that underwent a RHC in the French cohort, 80 were G1 tumors and 11 G2 (11\%). $20 \%$ of G1 and $27 \%$ of G2 tumors had LN metastases. Grading was not withheld as a risk factor. Another multicentric study which included patients who had undergone a $\mathrm{RHC}$ reported that $17 \%$ had a $\mathrm{Ki}-67>2 \%$ and $50 \%$ of them (2 of 4) had LN metastases (34). In our cohort, out of 16 patients with NET G1 and 6 with NET G2 sized $>2 \mathrm{~cm}$ that underwent RHC, 37,5\% $(\mathrm{n}=6)$ and $66,7 \%$ $(n=4)$ respectively had LN involvement. Although the number is small, it suggests that large tumors with higher Ki-67 index have more risk of LN metastasis.

The effect of positive LN in the development of distant metastases and in the survival of patients remains unclear $(30,33,37)$. In the pivotal trial of Moertel et al 7 out of 23 patients with appendiceal tumors $\geq 2 \mathrm{~cm}$ at presentation had metastatic disease (1). Looking more into detail, 4 of them had distant metastatic spread and 3 had metastases in locoregional LN.

Some patients with undiagnosed LN involvement may also not have relapse or a reduced survival. It is suggested that aNET may behave differently from other gastro-enteropancreatic NETs $(20,38)$. A large study involving 916 patients with intermediate size tumors found that regional lymphadenectomy was not associated with improved survival after 5 years, even among higher-grade tumors (37). A series of 619 patients from the Netherlands suggested a risk for metastatic spread of 1,6\% (39).

We believe this is the first paper showing complete data on national incidence of appendiceal NET. We have analyzed original pathology reports over a period of 6 years, showing the evolving quality in reporting in the community over the years. The mismatch between coding and original descriptions and the subsequent reclassification warrants us to be careful with conclusions retrieved from retrospective analyses from uncontrolled databases.

We acknowledge that our study has limitations. Information on surgical management is only retrieved by linking with the medical claims of the Belgian Health Insurance database. aNETs are often not discussed in tumor boards (40). This can be seen for instance in the numbers found in the DNET-registry, a prospectively kept database run by Belgian oncologists, where the number of appendiceal NETs is rather low. Larger numbers can be found in the BCR. Also, the study is retrospective in nature and because of missing data in established risk factors, the evidence concerning risk stratification for LN metastasis is not optimal.

Longer follow-up and better reporting of the currently recognized risk factors are required to determine which prognostic factors provide the better prediction on overall survival.

A strength of our study is the correction according to the latest WHO 2019 classification. Another strong point is that this is the first study that reflects management in the community and is free from selection bias usually found in single center cohorts or referral centers.

The quality of pathology reports in the community improved over time for grading, but other risk factors are often lacking. Complete reporting of risk factors is more frequent in tumors with intermediate size, where they influence clinical decision making.

Obligatory referral in pathology networks might not have a good cost-benefit ratio, as most aNETs are small and review by expert pathologists will increase the work load. Education of pathologists, surgeons, gastroenterologists and oncologists in the community will eventually improve reporting of risk factors, the same way reporting of Ki-67 index improved over time after its introduction in the classification system.

In conclusion, real NEC of the appendix are rare. Most aNETs are small G1 tumors. Size remains an important predictive factor for the presence of pathological regional lymph nodes : $46 \%$ of patients with a tumor larger than $2 \mathrm{~cm}$ had positive lymph nodes, with a higher frequency in G2 tumors. Positive LN are rarely found in patients with intermediate size aNETs.

\section{Conflict of interest}

None.

\section{References}

1. MOERTEL C.G.,WEILAND L.H., NAGORNEY D.M., DOCKERTY M.B. Carcinoid tumor of the appendix : treatment and prognosis. N. Engl. J. Med., 1987, 317(27) : 1699-1701. 
2. NIEDERLE M.B., HACKL M., KASERER K., NIEDERLE B. Gastroenteropancreatic neuroendocrine tumours: the current incidence and staging based on the WHO and European Neuroendocrine Tumour Society classification: an analysis based on prospectively collected parameters. Endocr. Relat. Cancer, 2010, 17(4) : 909-918.

3. YAO J.C., HASSAN M., PHAN A., DAGOHOY C., LEARY C., MARES J.E., et al. One hundred years after "carcinoid": epidemiology of and prognostic factors for neuroendocrine tumors in 35,825 cases in the United States. J. Clin. Oncol., 2008, 26(18) : 3063-3072.

4. RAULT-PETIT B., DO CAO C., GUYÉTANT S., GUIMBAUD R, ROHMER V., JULIÉ C., et al. Current Management and Predictive Factors of Lymph Node Metastasis of Appendix Neuroendocrine Tumors : A National Study from the French Group of Endocrine Tumors (GTE). Ann. Surg., 2019, 270(1) : 165-171

5. DASARI A., SHEN C., HALPERIN D., ZHAO B., ZHOU S., XU Y., et al. Trends in the Incidence, Prevalence, and Survival Outcomes in Patients With Neuroendocrine Tumors in the United States. JAMA Oncol., 2017, 3(10): 1335-1342.

6. DESCHAMPS L., COUVELARD A. Endocrine tumors of the appendix : a pathologic review. Arch. Pathol. Lab. Med., 2010, 134(6) : 871-875.

7. KLIMSTRA D.S., MODLIN I.R., COPPOLA D., LLOYD R.V., SUSTER $\mathrm{S}$. The pathologic classification of neuroendocrine tumors : a review of nomenclature, grading, and staging systems. Pancreas, 2010, 39(6) : 707712 .

8. MCCALL C.M., SHI C., CORNISH T.C., KLIMSTRA D.S., TANG L.H., BASTURK O., et al. Grading of well-differentiated pancreatic neuroendocrine tumors is improved by the inclusion of both Ki67 proliferative index and mitotic rate. Am. J. Surg. Pathol., 2013, 37 : 1671-7.

9. KLIMSTRA D.S., KLÖPPEL G., LA ROSA S., RINDI G. Classification of neuroendocrine neoplasms of the digestive system. In : WHO Classification of Tumours Editorial Board editors. WHO classification of tumours of the digestive system. 5th ed. Lyon : IARC, 2019 : 16-9.

10. UCCELLA S., SESSA F., LA ROSA S. Diagnostic Approach to Neuroendocrine Neoplasms of the Gastrointestinal Tract and Pancreas. Turk. Patoloji. Derg., 2015, 31(1) : 113-27.

11. MORIS D., TSILIMIGRAS D.I., VAGIOS S., NTANASIS-STATHOPOULOS I., KARACHALIOU G.S., PAPALAMPROS A., et al. Neuroendocrine Neoplasms of the Appendix: A Review of the Literature. Anticancer Res., 2018, 38(2) : 601-611.

12. BUSICO A., MAISONNEUVE P., PRINZI N., PUSCEDDU S., CENTONZE G., GARZONE G., et al. Gastroenteropancreatic High-Grade Neuroendocrine Neoplasms : Histology and Molecular Analysis, Two Sides of the Same Coin. Neuroendocrinology, 2020, 110(7-8) : 616-629.

13. MCGORY M.L., MAGGARD M.A., KANG H., O'CONNELL J.B., KO C.Y. Malignancies of the appendix : beyond case series reports. Dis. Colon Rectum, 2005, 48(12) : 2264-2271.

14. O'DONNELL M.F., CARSON J., GARSTIN W.I.H. Surgical treatment of malignant carcinoid tumours of the appendix. Int. J. Clin. Pract., 2007, 61(3) : 431-437.

15. GOUZI J.L., LAIGNEAU P., DELALANDE J.P., FLAMANT Y., BLOOM E., OBERLIN P., FINGERHUT A. Indications for right hemicolectomy in carcinoid tumors of the appendix. The French Associations for Surgical Research. Surg. Gynecol. Obstet., 1993, 176(6) : 543-547.

16. MACGILLIVRAY D.C., SYNDER D.A., DRUCKER W., REMINE S.G. Carcinoid tumors: the relationship between clinical presentation and the extent of disease. Surgery, 1991, 110(1) : 68-72.

17. PAPE U.F., NIEDERLE B., COSTA F., GROSS D., KELESTIMUR F., KIANMANESH R., et al. ENETS Consensus Guidelines for Neuroendocrine Neoplasms of the Appendix (Excluding Goblet Cell Carcinomas). Neuroendocrinology, 2016, 103(2) : 144-152.

18. TOUMPANAKIS C., FAZIO N.M., TIENSUU JANSON E., HÖRSCH D., PASCHER A., REED N., et al. Unmet needs in appendiceal neuroendocrine neoplasms. Neuroendocrinology, 2019, 108(1) : 37-44.

19 FRITZ A., PERCY C., JACK A., SHANMUGARATNAM K., SOBIN L., PARKIN D.M., et al. Coding guidelines for topography and morphology. In : FRITZ A. (ed). International classification of diseases for oncology (ICD-O). 3rd edition. Geneva : World Health Organization, 2013 : 19-69.

20. SANDOR A., MODLIN I.M. A retrospective analysis of 1570 appendiceal carcinoids. Am. J. Gastroenterol., 1998, 93(3) : 422-428.

21. BELGIAN CANCER REGISTRY, 2020, Cancer Burden in Belgium, 20042017, Belgian Cancer Registry, viewed 10 June 2020, https://kankerregister. org/Publications

22. MCCUSKER M.E., COTÉ T.R., CLEGG L.X., SOBIN L.H. Primary malignant neoplasms of the appendix : a population-based study from the surveillance, epidemiology and end-results program, 1973-1998. Cancer, 2002, 94(12) : 3307-3312.
23. PLÖCKINGER U., COUVELARD A., FALCONI M., SUNDIN A., SALAZAR R., CHRIST E., et al. Consensus Guidelines for the Management of Patients with Digestive Neuroendocrine Tumours : Well-Differentiated Tumour/Carcinoma of the Appendix and Goblet Cell Carcinoma. Neuroendocrinology, 2008, $87: 20-30$.

24. SHI C., ADSAY V., BERGSLAND E.K., BERLIN J., BRANTON P.A., FITZGIBBONS P.L., et al, 2020, Protocol for the Examination of Specimens From Patients With Neuroendocrine Tumors (Carcinoid Tumors) of the Appendix, College of American Pathologists (CAP), viewed 10 June 2020, https://www.cap.org/protocols-and-guidelines/cancer-reporting-tools/cancerprotocol-templates

25. DAVENPORT E., COURTNEY E.D., BENSON-COOPER S., BISSETT I.P. Appendiceal neuroendocrine neoplasms in the era of laparoscopic appendicectomy. Should we change surgical technique? ANZ J. Surg., 2014, 84(5) : 337-340.

26. GROTH S.S., VIRNIG B.A., AL-REFAIE W.B., JAROSEK S.L., JENSEN E.H., TUTTLE T.M. Appendiceal carcinoid tumors : Predictors of lymph node metastasis and the impact of right hemicolectomy on survival. J. Surg. Oncol., 2011, 103(1) : 39-45.

27. RICCI C., INGALDI C., ALBERICI L., BRIGHI N., SANTINI D., MOSCONI C., et al. Histopathological diagnosis of appendiceal neuroendocrine neoplasms : when to perform a right hemicolectomy? A systematic review and meta-analysis. Endocrine, 2019, 66(3) : 460-466.

28. BERNICK P.E., KLIMSTRA D.S., SHIA J., MINSKY B., SALTZ L., SHI W., et al. Neuroendocrine carcinoma of the colon and rectum. Dis. Colon Rectum, 2004, 47(2) : 163-169.

29. MEHRVARZ SARSHEKEH A., ADVANI S., HALPERIN D.M., CONRAD C., SHEN C., et al. Regional lymph node involvement and outcomes in appendiceal neuroendocrine tumors : a SEER database analysis. Oncotarget, 2017, 8(59) : 99541-99551.

30. MULLEN J.T., SAVARESE D.M. Carcinoid tumors of the appendix : a population-based study. J. Surg. Oncol., 2011, 104(1) : 41-44.

31. VAN DE MOORTELE M., DE HERTOGH G., SAGAERT X., VAN CUTSEM E. Appendiceal cancer : a review of the literature. Acta Gastroenterol. Belg., 2020, 83(3) : 441-448.

32. LIU E., TELEM D.A., HWANG J., WARNER R.R., DIKMAN A., DIVINO C.M. The clinical utility of Ki-67 in assessing tumor biology and aggressiveness in patients with appendiceal carcinoids. J. Surg. Oncol., 2010, 102(4) : 338-341.

33. PAWA N., CLIFT A.K., OSMANI H., DRYMOUSIS P., CICHOCKI A., FLORA R., et al. Surgical Management of Patients with Neuroendocrine Neoplasms of the Appendix : appendectomy or More. Neuroendocrinology, 2018, 106(3) : 242-251.

34. GROZINSKY-GLASBERG S., ALEXANDRAKI K.I., BARAK D., DOVINER V., REISSMAN P., KALTSAS G.A., et al. Current size criteria for the management of neuroendocrine tumors of the appendix : are they valid? Clinical experience and review of the literature. Neuroendocrinology, 2013, 98(1) : 31-37.

35. GALANOPOULOS M., MCFADYEN R., DRAMI I., NAIK R., EVAN N., LUONG T.V., et al. Challenging the Current Risk Factors of Appendiceal Neuroendocrine Neoplasms: Can They Accurately Predict Local Lymph Nodal Invasion? Results from a Large Case Series. Neuroendocrinology, 2019, 109(2) : 179-186

36. VOLANTE M., DANIELE L., ASIOLI S., CASSONI P., COMINO A., COVERLIZZA S., et al. Tumor staging but not grading is associated with adverse clinical outcome in neuroendocrine tumors of the appendix: retrospective clinical pathologic analysis of 138 cases. Am. J. Surg. Pathol., 2013, 37(4) : 606-612.

37. NUSSBAUM D.P., SPEICHER P.J., GULACK B.C., KEENAN J.E., GANAPATI A.M., ENGIUM BR, et al. Management of 1- to 2-cm Carcinoid Tumors of the Appendix : Using the National Cancer Data Base to Address Controversies in General Surgery. J. Am. Coll. Surg., 2015, 220(5) : 894-903.

38. CARR N.J., SOBIN L.H. Neuroendocrine tumors of the appendix. Semin. Diagn. Pathol., 2004, 21(2) : 108-119.

39. QUAEDVLIEG P.F., VISSER O., LAMERS C.B., JANSSEN-HEIJEN M.L., TAAL B.G. Epidemiology and survival in patients with carcinoid disease in The Netherlands. An epidemiological study with 2391 patients. Ann. Oncol., 2001, 12(9) : 1295-1300.

40. CUYLE P.J., GEBOES K., CARTON S., CASNEUF V., DECAESTECKER J., DE MAN M., et al. Current practice in approaching controversial diagnostic and therapeutic topics in gastroenteropancreatic neuroendocrine neoplasm management. Belgian multidisciplinary expert discussion based on a modified Delphi method. Acta Gastroenterol. Belg., 2020, 83(4) : 643-653. 